\title{
Theory on Exploring Acceptance and Adoption of Digital Textbooks: A Guide for the Book Publishing Industry
}

\author{
Wan Noor Azhar Wan Sulaiman ${ }^{1}$. Siti Ezaleila Mustafa ${ }^{1}$
}

Published online: 3 July 2020

(c) Springer Science+Business Media, LLC, part of Springer Nature 2020

\begin{abstract}
An uncertain world due to the Covid-19 pandemic embarks the publishers to find the best solution when designing the digital textbook to meet the student's new norms. Therefore, understanding the theories of user acceptance and adoption of technology is very critical. Thus, this study aimed to analyze the existing literature on the theory used for exploring the acceptance and adoption of digital textbooks among students. Thirty-two studies guided by PRISMA's statement of Preferred Reporting Articles for Systematic Reviews and Meta-Analysis were acknowledged for the systematic evaluation of Scopus and Web of Science databases. This work provided two main contributions. First, the study delivered condensed information on the theory used in the acceptance and adoption of digital textbook usage which will guide the publishers to consider when designing the digital textbook. Second, the results provided insights into the relevance of a new aspect for future research in the digital textbook context.
\end{abstract}

Keywords Digital textbook · Acceptance and adoption - Theory $\cdot$ Systematic review

\section{Introduction}

In the world, almost countries have implemented various containment measures to break the coronavirus's infection chain (Covid-19), such as lockdown measures or Movement Control Order (MCO) [1]. The pandemic of Covid-19 triggered a VUCA (volatility, uncertainty, complexity, and ambiguity) world as well, which has a massive impact on the human behavior and economic sector, including the publishing industry. The condition also leads to the temporarily closing of the educational institution encompassing elementary to high school to university [2, 3]. The situation made the digital learning material emerge as the critical element

Wan Noor Azhar Wan Sulaiman

azyus81@gmail.com

1 Department of Media and Communication Studies, Faculty of Arts and Sciences, University of Malaya, 50603 Kuala Lumpur, Malaysia 
in delivering the knowledge to the student, including digital textbooks. Therefore, the publishers who are involved in digital textbook publishing have to understand the theory and variables or factors that will influence human behavior in adopting and accepting digital textbook, to satisfy the students' needs.

In tandem with the rapid growth of technology and the emerging of Covid19 pandemic, user behavior has highlighted to face a new norm which influence in adopting and accepting of new technologies. When accepting new technology, multiple variables, such as technical availability, comfort, consumer needs, safety, and usability [4-6], influence the user. Various new technology scenarios, including mobile games [7], virtual libraries [8], and e-learning [9, 10], have been discussed in the last decade to illustrate how consumers have approved and embraced the program.

The discussion needs to be extended to the educational media, such as digital textbooks as well. Currently, digital textbooks offer more benefits than paper textbooks because they have collaborative, interactive, and other true features [11-14]. A review of student recognition and approval will be a critical success factor in the various features implemented in digital textbooks. Failure to embrace and implement the use of digital textbooks in the student's process as a client may influence the design features or internal variables. Understanding the concept used is essential given the interplay in all features and variables.

Although many studies on digital textbook adoption and acceptance have been conducted, in-depth systematic investigations in terms of theory used remain lacking. Therefore, this study aims to fill the gap in understanding, identifying, and specifying the variables of theories used in examining the acceptance and adoption of the digital textbook among students. By applying a systematic approach in the literature review to analyze the variables and theories used, this study provides a general and fundamental overview of the reason utilization of theory on the acceptance and adoption of digital textbooks among students. As a result, this work will fill the gaps of existing literature, wherein the majority of systematic reviews are unrelated to the acceptance and adoption of digital textbooks from the students' perspective [15-17]. Besides, all the finding lead to the determining the most suitable factors that need to be considered by digital textbook publishers in understanding the user or student.

\section{Toward a Systematic Review Framework on the Acceptance and Adoption of Digital Textbooks Among Students}

This study was driven by the following research questions to address this objective and conduct a systematic review:

- What kind of theory was selected in examining the acceptance and adoption of digital textbooks among students? 
- In terms of antecedents, mediators, moderators, and consequences, what are the selected variables in examining the acceptance and adoption of digital textbooks among students?

- How does the purpose of studies affect the selection of theory in examining the acceptance and adoption of digital textbooks among students?

This work reviews the current literature on student acceptance and adoption of digital textbooks based on the above mentioned issues. This section aims to conduct a systematic assessment. The methodology and declaration of Preferred Reporting Items for Systematic Reviews and Meta-analyses (PRISMA) describing the data are presented in the second section. In this section, the scientific literature is also synthesized and reviewed to identify, select, and assess suitable studies on the acceptability and implementation of digital textbooks. The findings from the selected studies are synthesized in the third section to identify the trend of theory used, including variables. The findings of the three research questions are discussed in the fourth section to explain why the theory was selected. Finally, future studies are identified in the last section.

A systemic assessment was applied to ensure the robustness of this study because the analysis specified the problem clearly using coherent and explicit methods for the identification, choice, critical evaluation, and data collection, including the evaluation [18]. Moreover, a systematic review will ensure the formulation of a comprehensive strategy for identifying gaps and directions for future studies [18].

\section{Methodology}

This section explores the techniques in identifying studies on the acceptance and adoption of digital textbooks among students. This study aims to provide neutral information collection and evaluation based on the approach described in PRISMA [19]. It provides a compilation and evaluation of neutral information. The resources in Scopus and the Web of Science (WoS) are utilized in the systemic assessment, admissible and exclusion criteria, process assessment (identification, screening, eligibility), and data abstraction and analyses. PRISMA is used as a guideline in the examination of early studies, which undergoes several phases, namely, identification, screening, eligibility, and inclusion [19] (see Fig. 1). According to several scholars, three distinctive benefits are provided by the PRISMA technique as follows: (1) It defines clear study questions in systemic studies, (2) It identifies the inclusion and exclusion criteria, and (3) It attempts to examine a large database of scientific studies within a defined time $[18,20]$.

\section{Resources}

Two primary journal databases, namely, Scopus and the WoS, are used in the evaluation. WoS is a comprehensive database of more than 33,000 databases from 256 different fields, including behavior, IT, interdisciplinary social studies, and interactive 


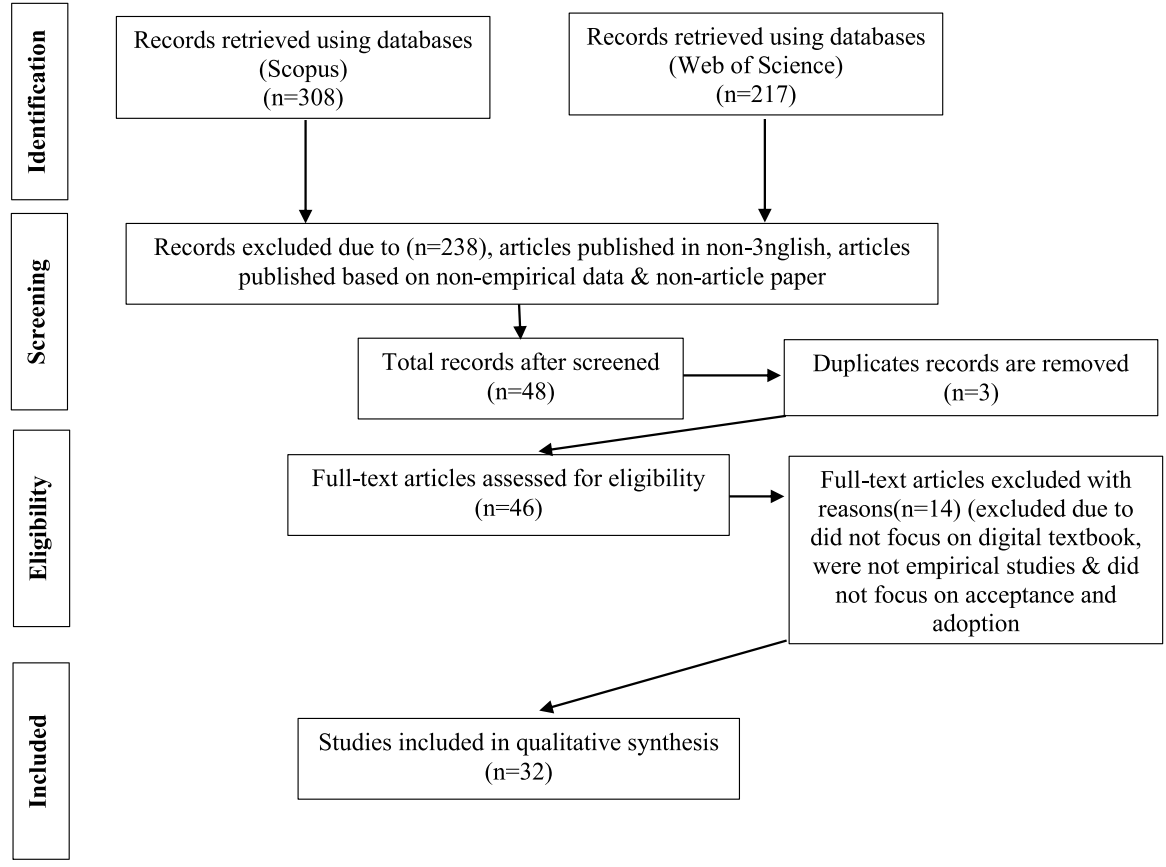

Fig. 1 Flow diagram of the study. (Adapted from [19])

learning. This database contains more than 100 years of complete historical records and quotations, which are generated and graded by Clarivate Analytics in three distinct steps. For comparison, Scopus is used as the second site. With over 22,800 newspapers written by 5000 authors, Scopus is a large abstract and quote base for peer reviews worldwide. This database covers a number of areas, including IT.

\section{Criteria of Eligibility and Exclusion}

Different eligibility and exclusion criteria were used. First, only empirical journals were chosen and review articles, a series of books, novels, chapters, and meetings were excluded. Second, search attempts excluded non-English publishing and concentrated only on English-language papers to prevent confusion and difficulty in translation. Third, for the timeline, a period of 8 years of publication was selected. This period is sufficient to observe the trend of theory used in the study of acceptance and adoption of digital textbooks. Given that the review focuses on the acceptance and adoption of digital textbooks among students, the indices of Social Science Citation, Emerging Sources Citation, Arts and Science Web, and Expanded Science Web were selected. However, the Directory of Open Access Journal (DOAJ) was excluded to ensure that this study was based on a high-credibility journal. Fourth, only peer-reviewed publications were chosen. Finally, in line with the objective 
of the study, only articles that focused on digital textbooks among students were selected (see Table 1).

\section{Process of Systematic Review}

The systematic evaluation technique involved four stages and was examined in early 2019. In the first phase, search keywords were identified. Similar keywords linked to electronic textbooks, acceptability, and adoption were used based on prior research and the thesaurus (Table 2). At this point, five duplicated articles were deleted after thorough screening.

The second phase is the screening phase. Among the 308 documents available for review, 238 studies were removed. The third phase consists of the qualification of posts. A maximum of 49 studies, some of which did not focus on the electronic text, were not analytical papers, and not based on acceptance and adoption. In the last step of the evaluation, 32 articles were used in the qualitative analyses (Fig. 1) As to the year of publishing, two, one, five, five, four, three, and four articles were published in 2019, 2018, 2017, 2016, 2015 and 2014, 2013, and 2012 and 2013, respectively. Four publications were made available in 2011.

\section{Data Abstraction and Analysis}

The other articles were evaluated and analyzed. Specific studies were considered to answer the questions formulated in "Toward a Systematic Review Framework on the Acceptance and Adoption of Digital Textbooks Among Students" section. The data were first extracted through the abstracts and then the complete article (in-depth) was considered in the choice of a suitable theory. The research method and purposes of the study were also noted.

\section{Result}

This review looks into 32 papers that focused on the recognition and execution of student study on digital textbooks. The principle used was also explored in three main roles, namely, the precedent, mediator, and moderator. The overview of the theory and variables is presented in Table 4. The consequences or outcome of the study could be classified as a particular behavioral goal and learning outcome through examination. The findings provided a thorough evaluation of the acceptance and adoption of current digital textbooks. 


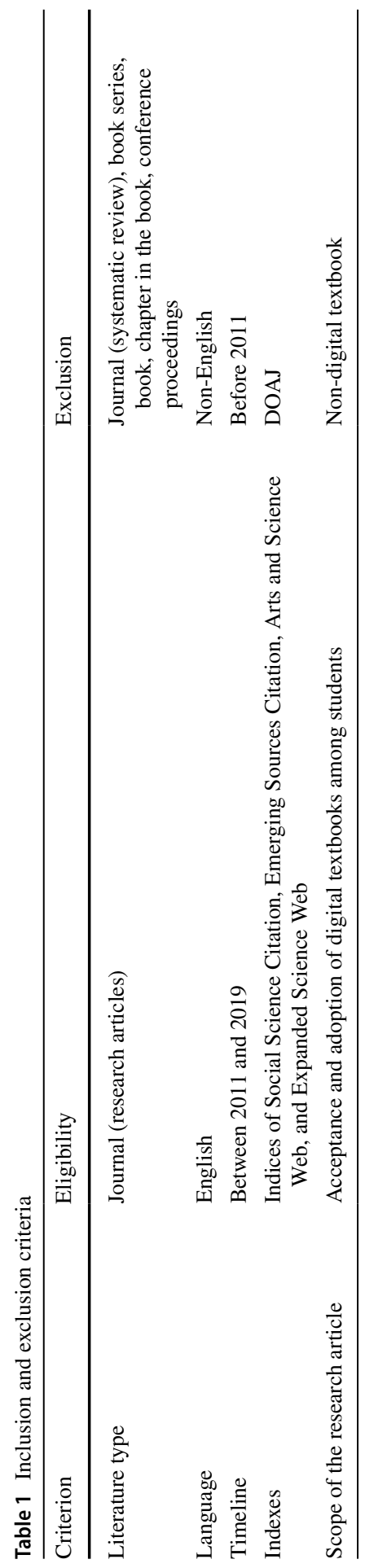


Table 2 Search string used in the systematic review process

\begin{tabular}{lc}
\hline Database & Keyword used \\
\hline Scopus & TITLE-ABS-KEY (("acceptance" \\
& OR "adoption") AND (e-book*, \\
& "electronic book*," "digital \\
book*," OR "digital textbook")) & TS $=(($ ("acceptance" OR "adop- \\
tion") AND ("e-book*," "elec- \\
tronic book*," "digital book*," \\
OR "digital textbook"))
\end{tabular}

\section{Analyzing the Type of Theory Used in Examining the Acceptance and Adoption of Digital Textbooks}

In previous studies, a number of theories were used to examine the students' worldwide acceptance and adoption of digital textbooks. Eight theories on the acceptance and adoption were used, namely, TTF [21], TAM [22], UTAUT [23], expectation confirmation model (ECM) [24], UTAUT 2 [25], student development theory (SDT) [26], social cognitive theory (SCT) [27], and innovation diffusion theory (IDT) [28]. The distribution of variables (antecedent, moderator, mediator, and consequence or outcome) based on the theory is presented in Table 4.

The evaluation data on the number of articles were checked to identify the type of theory used in the study that focused on the acceptance and implementation of the use of digital textbooks. The pattern and trend of the theory used were also observed. Analysis of Table 3 indicates that TAM was the dominant theory used in student acceptance and adoption of digital textbooks based. TAM was used as the theoretical framework in empirical studies between 2012 and 2018. However, TAM was implemented autonomously or combined with other theories. The three forms of theories, namely, IDT, UTAUT, and ECM, were also explored separately. TTF was used by SDT, SCT, and UTAUT 2 in an integrated system. Nine observational articles in the journal did not use any theories. The specifics of the theories used from 2011 to 2019 are shown in Table 3, including the number of theories. The following section also describes the detailed results related to the theory used.

\section{Discussion}

In this review of existing literature, a systematic analysis of the theories used in studies of the acceptance and adoption of digital textbooks among students was conducted. The analysis focused on studies with a span of 8 years. A strict review based on two databases was developed for 32 studies on the acceptance and adoption of digital textbooks to ensure that the goals of this study can be accomplished. 


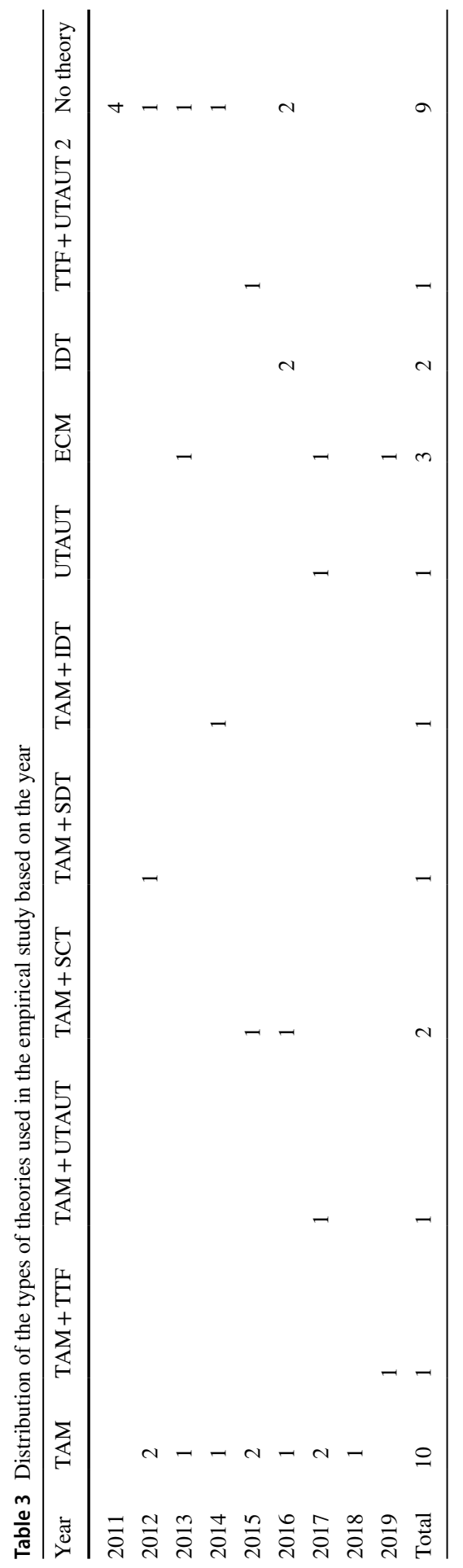




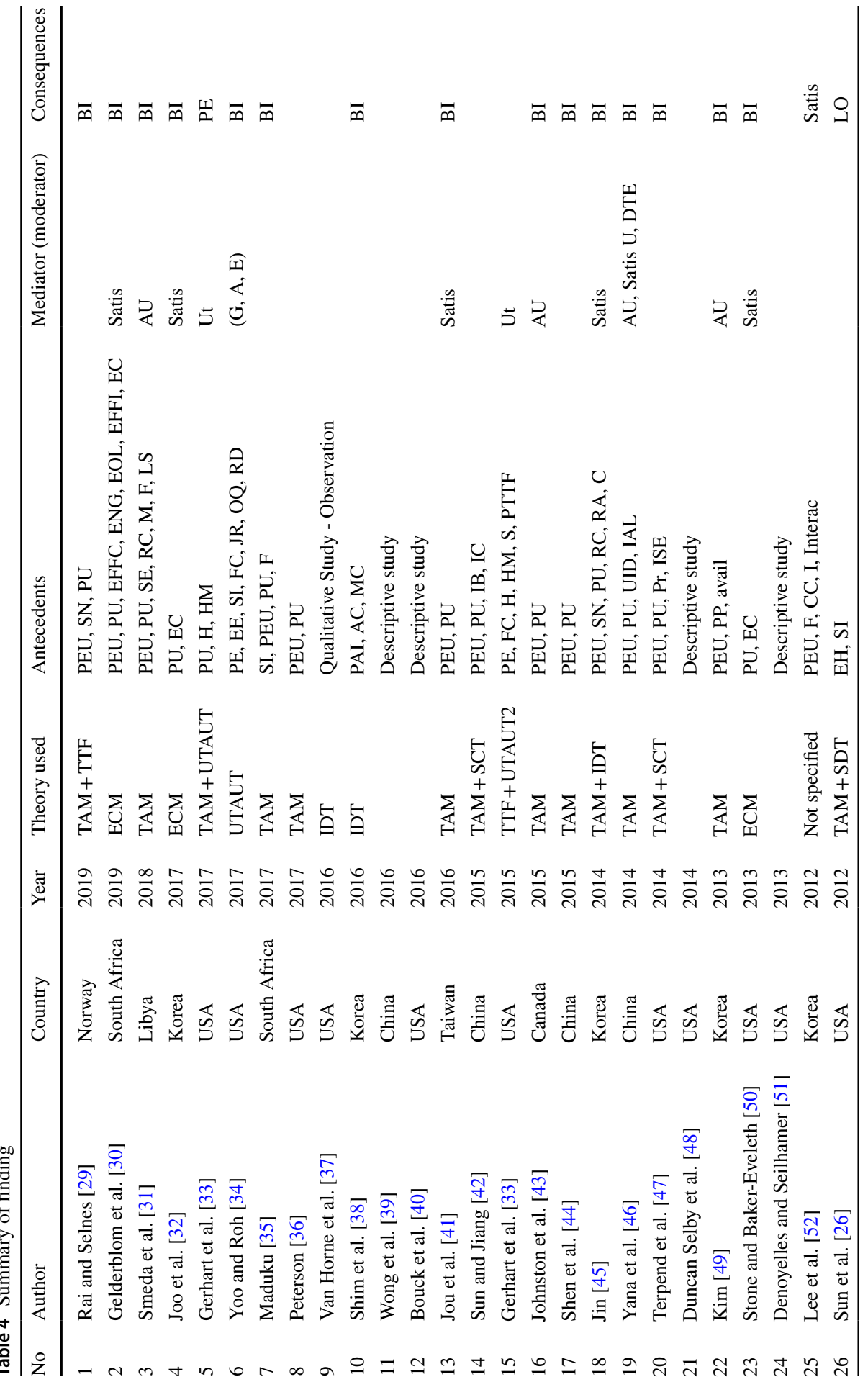




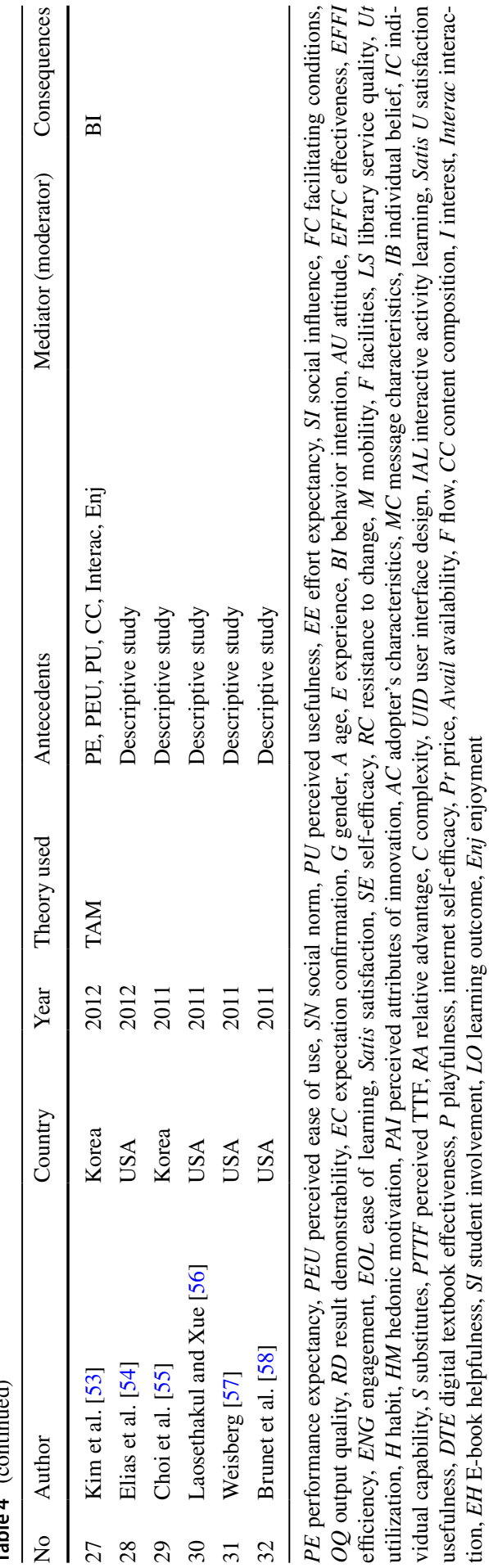




\section{Types of Theories Used}

Based on the 32 papers examined, TAM was the dominant theory in the acceptance of digital textbooks among students, followed by IDT, ECM, UTAUT, UTAUT 2, SCT, and SDT. Fifteen empirical study styles used TAM in their analysis as the theoretical framework.

When analyzing the acceptance of digital textbooks among students, TAM is the leading theoretical framework associated with success in various innovation acceptances. By further supporting this belief, the TAM article by Davis in 1989 had 424 journal quotes from the Social Science Citation Index (SSCI) at the beginning of 2000. Scopus web page analysis also showed that 17,321 references were cited with TAM's article in SSCI at the end of 2018.

In the past 20 years $[59,60]$, the scholars of IT have considered TAM as a parsimonious and powerful theory even if TAM is considered a model. The two major factors contributing to this insight are as follows: TAM can be used to investigate factors leading to the acceptance of IS and TAM is the starting point for the support and creation of a new IS embracing reality [61]. Based on this work, 10 studies used TAM independently. The work showed that TAM is a basic concept that can be used in examining the acceptance and adoption of digital textbooks. This situation matched the prevailing scholars' argument that TAM is the initial stage for investigating acceptance in IS [61].

Apart from TAM, ECM [30, 32, 50], and IDT [37, 38] have also been used to explore the acceptance and adoption of digital textbooks. Studies have shown the power of both theories in describing the actions of students' continuous intention toward digital textbooks. However, other studies have also shown that the integration of several theories provided a stronger model $[62,63]$ and reasonable result $[63,64]$. On the basis of such claims, the theory's ability to deliver good results and improve its characteristics $[65,66]$ could be defined as the theory with explanatory power.

Although ECM and IDT can produce a good outcome, these theories can be implemented only within a certain research context. For instance, ECM can be used in circumstances in which judgments on student satisfaction are influenced by discrepancies in standards with results in the digital textbook $[30,32,50]$. This finding is in line with Bhattacherjee's "expectation-confirmation model" [24], who believed that if the product met the user's needs, then the user would fulfill the results. Thus, the approach included the evaluation of students' expectations of the pre- and postuse of digital textbooks before fulfillment and intention to continue using digital textbooks.

IDT also excluded other theories $[37,38]$ in the same manner. The result revealed that IDT is not limited to the study of individual adoption and can be used for various purposes and contexts. Based on the reviewed studies using IDT, the adoption of digital textbooks by students was investigated throughout the period. In particular, before the students decide on whether to pursue technology adoption, they attempted to incorporate their actions in a digital textbook. This finding is in line with the statement of several well-known western scholars stated such that the process of 
acceptance in IDT was different from that of dissemination and diffusion, which is referred to as the cycle of human adoption [28, 67].

\section{Dominant Variables in Examining the Acceptance and Adoption of Digital Textbooks}

The data analysis in Table 3 indicated that 53 variables were used according to their respective theories. Perceived ease of use (PEOU) and perceived usefulness (PU) were the dominant variables applied in exploring students' intention to accept or adopt digital textbooks. This finding was also consistent with the domination of TAM as the theoretical framework in the reviewed articles.

Various articles did not use TAM as their research framework, but PEOU and PU were still considered in the research framework [30, 32, 50]. This condition indicated that PEOU and PU were significant factors in examining the usage of digital textbooks [66].

PEOU and PU were the key factors that provide a basis for illustrating the effect of external variables, such as intentions, attitudes, and internal beliefs. This finding can be seen in 15 out of 32 studies that applied PEOU and PU in the investigation of BI of students (see Table 3). Both factors have appeared together consistently because these factors interact with each other. Based on the TAM concept, new technology will be perceived as useful by the user if its ease to use is evident [22].

Previous studies have also indicated that external variables, such as PEOU and PU, are predictors. External variables are required in the studies because the students' actions in certain experiments should be defined and predicted. The software attributes are used in analyzing the acceptance and adoption of digital textbooks [46]. The PEOU and PU variables are used not only in digital textbook environments but also in other areas [68].

These variables were complementary to other variables and were also used to expand a theory or combine two theories. Several prominent scholars have explained that the integration of a theory involves the creation of a wide theory capable of producing consistent results and achieving the specific research aims $[46,66]$.

\section{Selection of Theories for Exploring the Acceptance and Adoption of Digital Textbooks Among Students}

Although many theories are available in studies on IS, only eight were used in studies on digital textbooks. Therefore, understanding the boundaries between the definition of acceptance and adoption is important. Although the words acceptance and adoption are often used interchangeably and are intertwined, these words have distinct meanings. A distinction must be made between technology adoption and acceptance in the context of digital textbooks. This distinction begins by establishing the awareness of consumers on the technology and ends with the use of this software [69]. 
Although the word acceptance is used inappropriately, this word refers to a technical solution with multiple variables. For example, a customer with a new technology product has not yet adopted it, then other phases exist and adoption rather than simply shopping is necessary. If the consumer buys a product and does not approve it, then full adoption is unlikely to occur [69]. Within the context of studies on digital textbooks, the scenario indicates that adoption occurs within certain periods through the exposure of an individual to digital textbooks. The acceptance of their digital textbook behavior was then measured in the research. Consequently, the adoption and acceptance were based on the previous inquiries that have been reviewed. For example, if the aim of the study was to examine student acceptance and adoption of digital textbooks and their intention to use, then several factors or variables should be introduced. For example, Jin [45] integrated TAM and IDT in their study. The combination of these theories is important because the goal of the study was to explore the adoption process before students could decide to take up the digital textbook and use it continuously. A selection of theories was also used because they aimed to explore the features or characteristics of digital textbooks and how these influence students' acceptance and adoption. To achieve this purpose, the original theory was incorporated with appropriate external variables. For example, Yana et al. [46] integrated the characteristics of interface design as a factor in examining the acceptance and adoption among students before their intention to use was decided. The usability of digital textbooks and how it influenced the selection of theory as the research framework was also explored. Fundamentally, the usability criteria could be a determinant in perceiving the ease of use construct and determining whether the usability of digital textbooks could influence the students' continued intention to use.

Various technology acceptance and adoption antecedents are identified in Table 3 based on previous studies. These antecedents can contribute to the knowledge of why some students are satisfied with digital textbooks and why certain students decide to continue using digital textbooks. The answers to these questions will influence the selection of theory used in the theoretical framework of this work. For example, Sun et al. [26] explored which factors obtained a positive sign to the learning outcome. To achieve this research goal, TAM and SDT were incorporated.

Although several studies have the same effect, the goal of this study was to examine the student's acceptance and adoption in another context, and a multiplicity of the theory emerged with a number of histories. According to the results in Table 4, the behavior of intention and learning outcomes need to be discussed although only two consequences and many antecedents were available because the scope of the purpose of the study was to be discussed. 


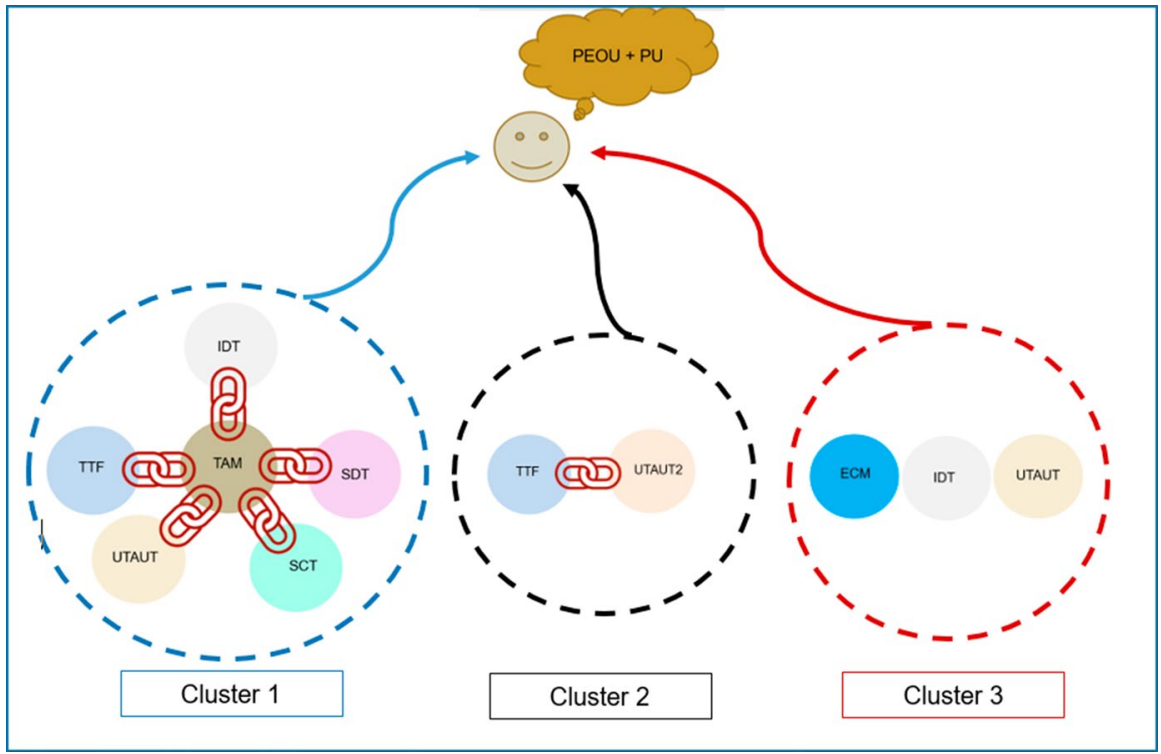

Fig. 2 The relationship between theory and factors to the student's adoption and acceptance of digital textbook

\section{The Relationship Between Theories and Factors for Exploring the Acceptance and Adoption of Digital Textbooks Among Students}

Figure 2 shows that there are three (3) clusters of theory used in understanding the adoption and acceptance among students towards digital textbooks. Cluster 1 was dominated by TAM and incorporated with the other theories. While for cluster two (2), it involved the combination between two theories consist of TTF and UTAUT2. Cluster three involved the exploration of adoption and acceptance of digital textbooks among students without any mixture of theory. All these three clusters are significant to satisfy the students' behavior, which is influenced by the dominance factors, namely, Perceive Ease of Use (PEOU) and Perceive Usefulness (PU). By establishing this conceptual as illustrated in Fig. 2, this will guide the publishers to prioritize which theory and factors need to be considered when exploring the adoption and acceptance of digital textbooks in a new norms scenario in the world today.

\section{Future Scope}

Much of the way students consider digital textbooks remains unclear and areas of analysis should be considered. First, the majority of current articles in the analysis were quantitative [70] and only one report was absolutely qualitative [71]. Future studies should consider additional mixed method designs or development 
methodologies of research. Such approaches can provide a qualitative perspective and enable a thorough evaluation and explanation of students' acceptance and adoption of digital textbooks.

Many acceptance and adoption studies were tested using the structural equation covariance model. Additional complex methods, such as structural equation modeling should be considered in future studies. Future research must also consider the use of the SME-PLS technique to evaluate the SME if less than 100 students have samples of the analysis. The technique can also be used adequately in small to medium sample sizes and non-distributive samples [72].

The literature overestimated the effects of inherent influences on the promotion of digital textbooks and ignored the extrinsic factors of students from technology and the environment [31]. Hence, future studies should consider, for instance, the functionalities of user interface and considerations different from the acceptance or approval of digital textbooks.

Multilevel work may be used in digital textbook research. Future studies could focus on the relationship between the top (i.e. entity, team, and organizational) and bottom (i.e., individual) entities in the new norms and explore the cross-level relationship between acceptance and outcomes. Bryk and Raudenbush [73] depicted a multilevel structure that fully understands the three levels of research (e.g., people in teams nested in organizations). Thus, future research can determine how the district level can affect the educational institution and person levels in terms of digital textbook adoption and acceptance.

\section{Conclusion}

This systematic analysis outlined the theories used to evaluate the acceptance and adoption of digital textbooks among students. Multiple suggestions were offered for future studies in the final analysis. Additional multifaceted methodological studies are required to achieve a detailed analysis and clarification of digital textbook acceptance and adoption. Besides, various techniques, such as source scan, quote, contacting experts, snowballing, and surveillance, were utilized to perform a systematic review of the literature. Formulating a clear framework for the theories used is also necessary to contribute to the acceptance and adoption of digital textbooks by students. Finally, in this study, a conceptual model of consideration factor towards adoption and acceptance is established as a guide to the digital textbook publishers.

\section{References}

1. Wiley M. Covid-19: countries around the world are reopening their schools. This is what it looks like. (May 2, 2020) Available at world economic forum: https://www.weforum.org/agenda/2020/05/ coronavirus-countries-schools-education-covid19-reopen-classroom/. Accessed 8 May 2020.

2. Billy $\mathrm{M}$. The influence of dynamic organizations and the application of digital innovations to educational institutions in the world during the Covid-19 pandemic (April 8, 2020). Available at SSRN: https://ssrn.com/abstract=3588233. Accessed 2 May 2020. 
3. School-closures-caused-by-coronavirus-(covid-19). [Online]. https://en.unesco.org/covid19/educa tionresponse. Accessed 09 May 2020.

4. Dapp TF, Stobbe A, Wruuck P, Keane B, Napier J, Sabadra A, Yamada Y, Speyer B, Deutsche Bank AG, Hoffmann R. The future of (mobile) payments 2012.

5. Meuter ML, Ostrom AL, Roundtree RI, Bitner MJ. Self-service technologies: understanding customer satisfaction with technology-based service encounters. J Mark. 2000;64(3):50-64.

6. Lai PC. Design and security impact on consumers' intention to use single platform E-payment. Interdiscip Inf Sci. 2016;22(1):111-22.

7. Ha I, Yoon Y, Choi M. Determinants of adoption of mobile games under mobile broadband wireless access environment. Inf Manag. 2007;44(3):276-86.

8. Park SY. An analysis of the technology acceptance model in understanding university students' behavioral intention to use e-learning. Educ Technol Soc. 2009;12(3):150-62.

9. Edmunds R, Thorpe M, Conole G. Student attitudes towards and use of ICT in course study, work and social activity: a technology acceptance model approach. Br J Educ Technol. 2012;43(1):71-84.

10. Park SY, Nam MW, Cha SB. University students' behavioral intention to use mobile learning: evaluating the technology acceptance model. Br J Educ Technol. 2012;43(4):592-605.

11. Fouh E, Breakiron DA, Hamouda S, Farghally MF, Shaffer CA. Exploring students learning behavior with an interactive etextbook in computer science courses. Comput Hum Behav. 2014;41:478-85.

12. Fouh E, Karavirta V, Breakiron DA, Hamouda S, Hall S, Naps TL, Shaffer CA. Design and architecture of an interactive etextbook-The OpenDSA system. Sci Comput Prog. 2014;88:22-40.

13. Gu X, Wu B, Xu X. Design, development, and learning in e-textbooks: what we learned and where we are going. J Comput Educ. 2015;2(1):25-41.

14. McFall R. Electronic textbooks that transform how textbooks are used. Electron Libr. 2005;23(1):72-81.

15. Hainey T, Connolly TM, Boyle EA, Wilson A, Razak A. A systematic literature review of gamesbased learning empirical evidence in primary education. Comput Educ. 2016;102:202-23.

16. Fokides E. Digital educational games and mathematics. Results of a case study in primary school settings. Educ Inf Technol. 2018;23(2):851-67.

17. ter Beek M, Brummer L, Donker AS, Opdenakker MCJ. Supporting secondary school students' reading comprehension in computer environments: a systematic review. J Comput Assist Learn. 2018;34(5):557-66.

18. Shaffril HAM, Krauss SE, Samsuddin SF. A systematic review on Asian's farmers' adaptation practices towards climate change. Sci Total Environ. 2018;644:683-95.

19. Moher D, Liberati A, Tetzlaff J, Altman DG. Preferred reporting items for systematic reviews and meta-analyses: the PRISMA statement. Ann Int Med. 2009;151(4):264-9.

20. Sierra-Correa PC, Kintz JRC. Ecosystem-based adaptation for improving coastal planning for sealevel rise: a systematic review for mangrove coasts. Mar Policy. 2015;51:385-93.

21. Fishbein M, Ajzen I. Belief, attitude, intention, and behavior: an introduction to theory and research 1977.

22. Davis FD, Bagozzi RP, Warshaw PR. User acceptance of computer technology: a comparison of two theoretical models. Manag Sci. 1989;35(8):982-1003.

23. Venkatesh V, Morris MG, Davis GB, Davis FD. User acceptance of information technology: toward a unified view. MIS Q. 2003;27:425-78.

24. Bhattacherjee A. Understanding information systems continuance: an expectation-confirmation model. MIS Q. 2001;25:351-70.

25. Venkatesh V, Thong JY, Xu X. Consumer acceptance and use of information technology: extending the unified theory of acceptance and use of technology. MIS Q. 2012;36(1):157-78.

26. Sun J, Flores J, Tanguma J. E-textbooks and students' learning experiences. Decis Sci J Innov Educ. 2012;10(1):63-77.

27. Bandura A. Social foundations of thought and action. NJ: Englewood Cliffs; 1986.

28. Rogers Everett M. Diffusion of innovations. New York, 12; 1995.

29. Rai RS, Selnes F. Conceptualizing task-technology fit and the effect on adoption-a case study of a digital textbook service. Inf Manag. 2019;56:103161.

30. Gelderblom H, Matthee M, Hattingh M, Weilbach L. High school learners' continuance intention to use electronic textbooks: a usability study. Educ Inf Technol. 2019;24(2):1753-76. 
31. Smeda A, Shiratuddin MF, Wong KW. A structural equation modelling approach for adoption of e-book amongst mathematics and statistics (MAS) students at higher education institutions in Libya. Int J Inf Learn Technol. 2018;35(4):240-54.

32. Joo YJ, Park S, Shin EK. Students' expectation, satisfaction, and continuance intention to use digital textbooks. Comput Hum Behav. 2017;69:83-90.

33. Gerhart N, Peak DA, Prybutok VR. Searching for new answers: the application of task-technology fit to e-textbook usage. Decis Sci J Innov Educ. 2015;13(1):91-111.

34. Yoo DK, Roh JJ. Adoption of e-books: a digital textbook perspective. J Comput Inf Syst. 2019;59(2):136-45.

35. Maduku DK. Understanding E-book continuance intention: empirical evidence from E-book users in a developing country. Cyberpsychol Behav Soc Netw. 2017;20(1):30-6.

36. Peterson DA. Electronic textbooks: usability of advanced features a limiting factor. Int J Mob Learn Organ. 2017;11(4):360-77.

37. Van Horne S, Russell JE, Schuh KL. The adoption of mark-up tools in an interactive e-textbook reader. Educ Tech Res Dev. 2016;64(3):407-33.

38. Shim D, Kim JG, Altmann J. Identifying key drivers and bottlenecks in the adoption of E-book readers in Korea. Telemat Inform. 2016;33(3):860-71.

39. Wong BTM, Li KC, Yuen KS, Wu JWS. Adopting and adapting open textbooks: schoolteachers' readiness and expectations. Int J Serv Stand. 2016;11(2):160-75.

40. Bouck EC, Weng PL, Satsangi R. Digital versus traditional: secondary students with visual impairments' perceptions of a digital algebra textbook. J Vis Impair Blind. 2016;110(1):41-52.

41. Jou M, Tennyson RD, Wang J, Huang SY. A study on the usability of E-books and APP in engineering courses: a case study on mechanical drawing. Comput Educ. 2016;92:181-93.

42. Sun Z, Jiang Y. How the young generation uses digital textbooks via mobile learning terminals: measurement of elementary school students in China. Br J Educ Technol. 2015;46(5):961-4.

43. Johnston DJ, Berg SA, Pillon K, Williams M. Ease of use and usefulness as measures of student experience in a multi-platform e-textbook pilot. Libr Hi Tech. 2015;33(1):65-82.

44. Shen H, Luo L, Sun Z. What affect lower grade learner's perceived usefulness and perceived ease of use of mobile digital textbook learning system? An empirical factor analyses investigation in China. Int J Multimed Ubiquitous Eng. 2015;10(1):33-46.

45. Jin $\mathrm{CH}$. Adoption of e-book among college students: the perspective of an integrated TAM. Comput Hum Behav. 2014;41:471-7.

46. Yana LIU, Minhuaa WU, Zhonga SUN. Extending the TAM model to explore the factors that affect intention to use digital textbooks in primary teachers' views. In: Workshop proceedings of the 10th international conference on intelligent environments, vol. 18. IOS Press; 2014, p. 127.

47. Terpend R, Gattiker TF, Lowe SE. Electronic textbooks: antecedents of students' adoption and learning outcomes. Decis Sci J Innov Educ. 2014;12(2):149-73.

48. Selby RD, Carter KP, Gage SH. Survey concerning electronic textbooks: assessing student behavior and environmental considerations. Int J Sustain High Educ. 2014;15(2):142-56.

49. Kim Y. A study of primary school teachers' awareness of digital textbooks and their acceptance of digital textbooks based on the technology acceptance model. J Dig Converg. 2013;11(2):9-18.

50. Stone RW, Baker-Eveleth L. Students' expectation, confirmation, and continuance intention to use electronic textbooks. Comput Hum Behav. 2013;29(3):984-90.

51. Denoyelles A, Seilhamer R. eTextbook access, usage, and beliefs: implications for adoption in higher education. J Appl Res High Educ. 2013;5(2):189-201.

52. Lee BG, Kim SJ, Park KC, Kim SJ, Jeong ES. Empirical analysis of learning effectiveness in u-learning environment with digital textbook. KSII Trans Internet Inf Syst. 2012;6(3):1-17.

53. Kim MR, Choi MA, Kim J. Factors influencing the usage and acceptance of multimedia-based digital textbooks in pilot school. KSII Trans Internet Inf Syst. 2012;6(6):1-11.

54. Elias EC, Phillips DC, Luechtefeld ME. E-books in the classroom: a survey of students and faculty at a school of pharmacy. Curr Pharm Teach Learn. 2012;4(4):262-6.

55. Choi JI, Heo H, Lim KY, Jo IH. The development of an interactive digital textbook in middle school English. In: International conference on future generation information technology. Berlin, Heidelberg: Springer; 2011, pp. 397-405.

56. Laosethakul K, Xue Y. A preliminary investigation of intention to use of an electronic textbook. Ubiquitous Learn Int J. 2011;3(4):113-26.

57. Weisberg M. Student attitudes and behaviors towards digital textbooks. Publ Res Q. 2011;27(2):188-96. 
58. Brunet DP, Bates ML, Gallo JR, Strother EA. Incoming dental students' expectations and acceptance of an electronic textbook program. J Dent Educ. 2011;75(5):646-52.

59. Venkatesh V, Davis FD. A theoretical extension of the technology acceptance model: four longitudinal field studies. Manag Sci. 2000;46(2):186-204.

60. Lucas HC Jr, Spitler VK. Technology use and performance: a field study of broker workstations. Decis Sci. 1999;30(2):291-311.

61. Lee Y, Kozar KA, Larsen KR. The technology acceptance model: past, present, and future. Commun Assoc Inf Syst. 2003;12(1):50.

62. Wu JH, Wang SC. What drives mobile commerce? An empirical evaluation of the revised technology acceptance model. Inf Manag. 2005;42(5):719-29.

63. Gillenson ML, Sherrell DL. Enticing online consumers: an extended technology acceptance perspective. Inf Manag. 2002;39(8):705-19.

64. Sigala M, Airey D, Jones P, Lockwood A. The diffusion and application of multimedia technologies in the tourism and hospitality industries. In: Information and communication technologies in tourism. Vienna: Springer; 2000, pp. 396-407.

65. Carter L, Bélanger F. The utilization of e-government services: citizen trust, innovation and acceptance factors. Inf Syst J. 2005;15(1):5-25.

66. Legris P, Ingham J, Collerette P. Why do people use information technology? A critical review of the technology acceptance model. Inf Manag. 2003;40(3):191-204.

67. Straub ET. Understanding technology adoption: theory and future directions for informal learning. Rev Educ Res. 2009;79(2):625-49.

68. Chen SC, Yen DC, Peng SC. Assessing the impact of determinants in e-magazines acceptance: an empirical study. Comput Stand Interfaces. 2018;57:49-58.

69. Day M, Demiris G, Oliver DP, Courtney K, Hensel B. Exploring underutilization of videophones in hospice settings. Telemed e-Health. 2007;13(1):25-32.

70. ŠUmak B, HeričKo M, PušNik M. A meta-analysis of e-learning technology acceptance: the role of user types and e-learning technology types. Comput Hum Behav. 2011;27(6):2067-77.

71. Renaud K, Van Biljon J. Predicting technology acceptance and adoption by the elderly: a qualitative study. In: Proceedings of the 2008 annual research conference of the South African institute of computer scientists and information technologists on IT research in developing countries: riding the wave of technology. ACM; 2008, pp. 210-9.

72. Chin WW, Newsted PR. Structural equation modeling analysis with small samples using partial least squares. Stat Strateg Small Sample Res. 1999;1(1):307-41.

73. Bryk AS, Raudenbush SW. Toward a more appropriate conceptualization of research on school effects: a three-level hierarchical linear model. In: Multilevel analysis of educational data. Academic Press; 1989, pp. 159-204.

Publisher's Note Springer Nature remains neutral with regard to jurisdictional claims in published maps and institutional affiliations. 